\title{
Application of a second-generation US contrast agent in infants and children-a European questionnaire-based survey
}

\author{
Michael Riccabona
}

Received: 28 December 2011 /Revised: 26 June 2012 / Accepted: 10 July 2012 /Published online: 3 October 2012

(C) Springer-Verlag 2012

\begin{abstract}
Background No US contrast agent (US-CA) is currently licensed for use in children.

Objective To survey the off-label use in children of a second-generation US-CA.

Materials and methods Questionnaires were e-mailed to European paediatric radiologists, who were asked about their experience with the second-generation US-CA Sonovue $^{\circledR}$ (Bracco, Milan, Italy). Number of examinations per indication and adverse effects were recorded. Examinations were categorised by intravenous or intracavitary use of US-CA.

Results Out of 146 respondents, 88 stated that they did not perform contrast-enhanced US in children, but 36 of these $(44 \%)$ would appreciate paediatric approval. Fortyfive centres reported 5,079 examinations in children (age mean: 2.9 years; range: birth-18 years, M/F: 1/ 2.8). The majority $(4,131[81 \%]$ in 29 centres) were
\end{abstract}

Representing the: European Society of Paediatric Radiology (ESPR) Uroradiology Task Force and European Society of Urogenital Radiology (ESUR) Paediatric Work Group

Members: Avni FE, Blickman J, Damasio B, Darge K, Lobo ML, Ording-Mueller LS, Papadopoulou F, Riccabona M (chair), Vivier PH, Willi U.

M. Riccabona $(\bowtie)$

Department of Radiology, Division of Paediatric Radiology, Universitätsklinikum LKH Graz,

Auenbruggerplatz 34,

8036, Graz, Austria

e-mail: michael.riccabona@klinikum-graz.at intravesical applications. The minority (948 [19\%] in 30 centres) were intravenous applications. No adverse effects had been recorded from intravesical use. Six minor adverse effects (skin reaction, unusual taste, hyperventilation) had been recorded after five intravenous studies $(0.52 \%)$.

Conclusion Responses suggest a favourable safety profile of this second-generation US-CA in children. It also demonstrates a demand for such US-CA from paediatric radiologists.

Keywords Contrast-enhanced ultrasound $\cdot$ Child $\cdot$ Voiding urosonography

\section{Introduction}

The recent worldwide efforts to reduce the radiation burden caused by diagnostic imaging, particularly in children, has created an increased need for alternative, reliable and non-ionising imaging tools. The well-documented hazards of diagnostic radiation, especially during the first decade(s) of life, add further importance to the need to optimally exploit the diagnostic potential of ultrasound (US) as a noninvasive and nonirradiating imaging tool; its potential can possibly be enhanced significantly by a US contrast agent (US-CA) for some selected queries and conditions.

In Europe, the use of US-CAs is approved for a limited number of indications in adults, i.e. echocardiography, large ("macro") blood vessels, breast and liver conditions. At present, there is no approved US-CA for 
paediatric use. The only US-CA (i.e. Levovist ${ }^{\circledR}$, Schering, Berlin, Germany) approved for paediatric intravenous (IV) and intracavitary use in some European countries was taken off the market for economic reasons some years ago. As soon as an approved US-CA was available - despite the obstacle of lacking paediatric registration at present-US-CAs have been used in infants and children in many countries over the last 15 years, particularly in Europe. The most frequent paediatric application is contrast-enhanced voiding urosonography (ce-VUS) for assessment of vesicoureteral reflux (VUR) [1-24]. Levovist ${ }^{\circledR}$ was the agent most frequently used, since it had been approved for paediatric intravesical use in some countries. For this application, a procedural recommendation has been developed and issued by the Uroradiology Task Force of the European Society of Paediatric Radiology (ESPR) and the Paediatric Work Group of the European Society of Urogenital Radiology (ESUR) to promote standardised high-quality examinations [25]. All the experience with US-CAs led to recommendations by the World Federation of Ultrasound in Medicine and Biology (WFUMB) as well as the European Federation of Societies on Ultrasound in Medicine and Biology (EFSUMB) on the use of CE-US [26] which included paediatric applications, particularly in the 2008 and 2011 updates [27, 28]; the proposed indications include both IV and intracavitary applications. The recommended paediatric indications are assessment of focal lesions of parenchymal abdominal organs (e.g. in trauma or in oncology conditions) and the assessment of VUR by intravesical US-CA administration (= ce-VUS) [28, 29]. The list of indications will increase in the future as demonstrated by trials analysing the clinical potential and impact of CE-US, particularly in adult but also in paediatric oncology. All these experiences demonstrate that CE-US can contribute significantly to reducing the diagnostic radiation burden to the population.

But, at present, all paediatric US-CA applications remain off-label; a situation that does not match the clinical need. For instance, in the setting of mild blunt abdominal trauma, imaging (and follow-up) by CT would involve a significant radiation exposure and iodinated CA injection (potentially even repeatedly); this might partially be replaced by CE-US. However, physicians must obtain an informed consent for off-label use of US-CA. Similar reasoning holds for the assessment of VUR. These examples illustrate why approval for paediatric use is deemed urgently necessary.

To address this need, and to try to confirm the safety of US-CAs in children, the ESPR Uroradiology Task Force together with the ESUR Paediatric Working Group set out to help provide data and information on the use and safety of the most common second generation US-CA presently available in Europe, i.e. SonoVue $^{\circledR}$ (Bracco, Milano, Italy), used for paediatric applications, by initiating a Europe-wide survey. Responses from this survey are presented.

\section{Materials and Methods}

Questionnaires were distributed in summer 2010 via email to all members of the ESPR and the Society of German-speaking Paediatric Radiologists (Gesellschaft pädiatrische Radiologie [GPR]) as well as other physicians and groups who requested or offer to participate to support our efforts (partially also via personal and individual contacts), all being considered potential users of this US-CA in children, i.e. general radiologists, paediatricians, paediatric urologists, members of affiliated societies (e.g. ESUR, Austrian Society for Ultrasound in Medicine [OEGUM], Austrian Society for Radiology [OERG]), and customers known to the manufacturer Bracco (Milan, Italy). Replies were accepted until April 2011.

The questionnaire asked for specific information on number of paediatric applications, mean age and gender, on the individual application (IV or intracavitary), and on all observed adverse events associated with the USCA. Furthermore, in IV CE-US, the targeted organ and the clinical query/indication were to be listed. The type and duration of US-CA usage in children needed to be filled out. The completed questionnaire could be returned by fax, regular mail or e-mail with identification of the submitting institution. It was promised that the submitted data would not be used for any undertaking or research other than this ongoing survey, and that the various nonrelevant details (name of institution, etc.) would be kept anonymous. Only reports on the use of SonoVue ${ }^{\circledR}$ were evaluated; data on Levovist ${ }^{\circledR}$ applications were not included. To avoid duplicate data and data overlap from one institution with several individuals filing the survey, only one completed survey per institution was used. 
The central questions asked about experience with contrast-enhanced US in a questionnaire sent European paediatric radiologists

\section{Questionnaire on contrast-enhanced ultrasound (CE-US) in children}

Do you or have you used US contrast agents in children?

$\square$ Yes $\square$ No

Do you or have you used SonoVue ${ }^{\circledR}$ in infants and children?

Yes $\square$ No

If Yes: Since when have you used SonoVue ${ }^{\circledR}$

how many exams how many exams / year

intravenous intravesical (for VUR detection)

which other US contrast do / did you use

Have you performed or do you perform contrast-enhanced voiding urosonography (ce-VUS)

for the detection vesicoureteral reflux in children using SonoVue ${ }^{\circledR} \quad \square$ Yes $\quad \square$ No

If YES: Since when have you performed ce-VUS.........., since when have you used SonoVue ${ }^{\circledR}$

Number of exams number of exams / year.

Mean patient age (years), range (years), gender ratio

Number of contrast agent related side effects

If YES, please give age and gender of affected patient(s)

Please describe adverse effects:

Have you performed or do you perform intravenous SonoVue ${ }^{\circledR}$ applications in children? $\square$ Yes $\square$ No

If YES: Since when have you performed CE-US since when have you used SonoVue ${ }^{\circledR}$

Number of exams / patients , number of exams / year.

Mean patient age (years), range (years), gender ratio

Indications (number, age, gender):

Trauma

Targeted organs (number, age, gender):

Tumors and mass lesions

Liver

Inflammation

Spleen

Vessel patency

Pancreas

Others (please name)

Kidney

Brain

Major vessels

Others

Number of contrast agent related side effects

If YES: please give age and gender of affected patient(s)

Please describe kind of reaction 


\section{Results}

A total of 146 surveys were received, 88 of which simply stated that no CE-US was performed in children at the respective institution because of regulatory issues or availability. Nevertheless, $44 \%$ of the $88(n=36)$ stated that they would appreciate paediatric approval to then start using USCAs in children. Nine centres reported that they had been using Levovist ${ }^{\circledR}$, but stopped CE-US after Levovist ${ }^{\circledR}$ became unavailable. Four data sets were incomplete or mixed with adult applications (without age information that would allow the paediatric cohort to be identified) and could not be used; however, in two of these surveys, two adverse events were reported in adolescents (one severe anaphylactic reaction and one urticaria, both after IV use of SonoVue $\left.{ }^{\circledR}\right)$.

Forty-five centres from all over Europe reported on paediatric applications of SonoVue ${ }^{\circledR}$, documenting 5,079 examinations in total. Thirty-one centres performed both IV and intracavitary CE-US, the others reported the use of either IV CE-US or ce-VUS. The number of patients could not be retrieved from these data, but appears to be less than the above number, as some patients may have undergone repeated examinations. The highest number of responses [23] came from Germany. The other countries were-in alphabetical order-Austria, Finland, France, Greece, Hungary, Italy, Norway, Poland, Romania, Slovenia, Spain, Sweden and Switzerland. Mean patient age was 2.9 years (range: birth to 18 years), gender distribution was 1 male to 2.8 females. Most centres started to use SonoVue ${ }^{\circledR}$ between 2006 and 2009, only a few reported using SonoVue ${ }^{\circledR}$ from 2001 onwards; i.e. when the agent was first introduced. This indicates a frequency of approximately 100 to 1,000 investigations per year in earlier years. In 2010 - the last complete year covered and included in the survey-there were approximately 2,000 examinations. Twenty centres had been using Levovist ${ }^{\circledR}$ before switching to SonoVue ${ }^{\circledR}$. For the other questionnaires, the respective answer (as to whether CE-US has been performed with Levovist before starting to use SonoVue) was partially missing in the respective field.

The most extensive experience with CE-US exists in centres that perform a large number of ce-VUS. Between 400 and 700 ce-VUS studies were reported in four centres; the majority of institutions reported 50-300 examinations (Table 1). IV applications of CE-US are used less frequently. Many reported only small series with up to 10 case studies, the rest between 10 and 80 patients, except for one large series of nearly 500 patients (Table 2). All six mild side effects of SonoVue ${ }^{\circledR}$ that could be attributed solely to the US-CA were reported in five patients with IV applications.

A total of 4,131 intracavitary applications (81.3\%) was reported from 29 centres, nearly all intravesical (Table 1). Only three groups mentioned other intra-cavitary applications, such as assessment of drain position and function during or after percutaneous interventions-no exact number available (probably $<1 \%$ ). The mean patient age in the intra-cavitary use group was 2.5 years (range: newborn to 18 years, gender distribution $=1$ male to 3 females). No side effect could be attributed solely to the US-CA for ce-VUS; the few complaints reported were most likely from catheterisation. This matches with the result from a literature meta-analysis, where no significant side effects could be attributed clearly to SonoVue ${ }^{\circledR}$; the few minor symptoms reported with Levovist ${ }^{\circledR}$ were also probably due to the catheter itself.

Thirty centres reported 948 IV examinations (18.7\%) (Table 2). The mean patient age was 5 years (range: newborn to 18 years, gender distribution: 1 male to 2 females). The most frequently targeted organ was the liver, rarer the spleen, less frequently the kidney and pancreas, with a few additional applications such as the ovary or vessels. The indications were mostly oncological, traumatic or inflammatory conditions - either lesion detection (e.g. in subacute or moderate trauma) or lesion characterisation (e.g. abscess vs tumour) - or some dedicated rare queries (such as transplant and vascular examinations). Five patients were reported to have had six minor side effects after IV US-CA administration, with one having two symptoms (i.e. strange taste and skin reaction). The symptoms were minor skin reaction $(n=2$, urticaria or rash), unusual taste $(n=3)$ and hyperventilation $(n=1)$. One severe anaphylactic reaction necessitating resuscitation measures was reported in an adolescent girl suffering form an oncological condition (not included in the survey population, as patients older than 18 years were not the target of the survey) after repeated US-CA application and with numerous other known allergies.

\section{Discussion and conclusion}

US-CAs were introduced initially for cardiac use about 25 years ago. At that time, they were not able not to pass the lung capillaries and thus were used mainly for assessment of (intracardiac or intrapulmonary) shunts [30-32]. Technical developments then created smaller micro-bubble carriers that enabled smaller and more stable US-CAs to pass the capillary bed, with a better signal response and constantly increasing contrast enhancement duration [30, 32, 33]. Basically, all US-CAs consist of some gas micro bubbles (e.g. air, perfluorocarbon, sulphur-hexafluoride, etc.) attached to a carrier molecule (either a protein-, a sugar- or a lipid-macromolecule) that acts as a shell, stabilised usually by palmitic acid. US-CAs not only increase US reflexion, but also emit additional US signals by their harmonic response [32-37]. These can be visualised by a 
Table 1 Survey results: detailed results from responses concerning contrast-enhanced voiding urosonography (ce-VUS). $C A$ Contrast agent

\begin{tabular}{|c|c|c|c|c|c|c|c|}
\hline & Number of exams & Mean age (years) & Age range (years) & Male: female & SonoVue since & CA before & Adverse effects \\
\hline & 500 & 2 & $0-5$ & $1: 2.5$ & 2009 & Levovist & None \\
\hline & 12 & 1 & $0-12$ & $1: 11$ & 2009 & Levovist & None \\
\hline & 4 & 0.5 & $?$ & $0: 7$ & 2008 & Levovist & None \\
\hline & 315 & 2 & $0-17$ & $1: 1$ & 2009 & Levovist & None \\
\hline & 15 & $?$ & $?$ & $?$ & $2004(-7)^{\mathrm{a}}$ & None & None \\
\hline & 700 & 1.5 & $0-16$ & $?$ & 2004 & None & None \\
\hline & 120 & 1.6 & $0-18$ & $1: 5$ & 2007 & Levovist & None \\
\hline & 10 & 0.5 & $0-1$ & $?$ & 2007 & None & None \\
\hline & 40 & 4.5 & $0-15$ & $1 \mathrm{t}: 3$ & $2003(-4)^{\mathrm{a}}$ & Levovist & None \\
\hline & 500 & 0.55 & $0-4$ & $1: 1$ & 2009 & None & None \\
\hline & 450 & $?$ & $0-15$ & 1: 9 & 2006 & None & None \\
\hline & 8 & 1 & $0-3$ & $1: 2$ & 2009 & Levovist & None \\
\hline & 200 & 1 & $0-4$ & $2: 8$ & 2008 & Levovist & None \\
\hline & 10 & 8 & $0-18$ & $8: 2$ & 2006 & None & None \\
\hline & 160 & 4.6 & $0.5-16$ & $2: 8$ & 2008 & Levovist & None \\
\hline & 25 & 1 & $0-2$ & $?$ & 2010 & None & None \\
\hline & 50 & 12 & $7-16$ & $1: 3$ & 2009 & None & None \\
\hline & 5 & 10 & $7-13$ & $0: 1$ & 2009 & Levovist & None \\
\hline & 180 & 3.6 & $0-18.5$ & $1: 2$ & 2010 & Levovist & None \\
\hline & 55 & 2 & $0-12$ & 1: 1 & 2010 & Levovist & None \\
\hline & 2 & 4 & $2-6$ & $0: 2$ & 2004 & Levovist & None \\
\hline & 2 & 9.5 & $8-11$ & 1: 1 & 2011 & Levovist & None \\
\hline & 240 & 2 & $1-10$ & $2.5: 1$ & 2007 & None & None \\
\hline & 33 & 7 & $0-10$ & $2: 1$ & 2009 & None & None \\
\hline & 200 & 0.5 & $1-18$ & 1: 10 & 2007 & Levovist & None \\
\hline & 38 & 1.8 & $0-11$ & 21: 17 & 2010 & Levovist & None \\
\hline & 1 & 8 & 8 & 1 & 2011 & Levovist & None \\
\hline & 76 & 5.7 & 0-19 & $1: 2$ & 2001 & Levovist & None \\
\hline & 180 & 1 & $0.5-3$ & $1: 3$ & 2007 & Levovist & None \\
\hline \multicolumn{8}{|c|}{29 centres } \\
\hline Total & 4,131 & 2.5 & $0-19$ & ca. $1: 3$ & & & None \\
\hline
\end{tabular}

${ }^{a}$ Data are provided only for the given time span (e.g. because not used before or since)

variety of US techniques, both with basic grey scale imaging or using more novel techniques such as harmonic imaging and pulse inversion, Doppler techniques and other dedicated contrast visualisation tools are presently incorporated in practically all high-end US systems, based partially on nonfundamental response [32, 38-40]. More recently, low mechanical index ("low-MI") contrast imaging techniques have enabled an even longer duration of adequate signal response with very little US-CA destruction, thus improving real-time assessment of enhancement dynamics.

In adults, numerous applications have been assessed and reported in the literature - particularly the use of US-CAs for lesion detection and characterisation in abdominal parenchymal organs (predominantly the liver) [32, 41-52]. These reports demonstrate not only a high diagnostic potential and reliability of CE-US, but also a high safety profile of US-CAs; in adults, anaphylactoid reactions have been reported at a low rate of less than $0.002 \%[53,54]$. The established indications are oncological, traumatic or inflammatory lesions, assessment of vascular patency or pathology, tissue perfusion, echocardiography, intraoperative guidance and transplant queries [32, 55-70].

So what is the actual evidence for using CE-US in children? It is clear that CE-US delivers reliable diagnostic information for a variety of conditions, particularly in adults. In children, the diagnostic value of ce-VUS has been studied extensively. These studies demonstrate that ce-VUS is a practical unique paediatric application of US-CAs that has gained widespread acceptance over the past few years after its introduction in the mid-1990s. Initial restrictions, 
Table 2 Survey results: detailed results from responses concerning intravenous contrast-enhanced ultrasound (CE-US) data

\begin{tabular}{|c|c|c|c|c|c|c|c|}
\hline & $\begin{array}{l}\text { Number } \\
\text { of exams }\end{array}$ & $\begin{array}{l}\text { Mean age } \\
\text { (years) }\end{array}$ & $\begin{array}{l}\text { Age range } \\
\text { (years) }\end{array}$ & Male: female & SonoVue since & CA before & Adverse effects \\
\hline & 13 & 5 & $1-16$ & $5: 8$ & 2009 & Levovist & None \\
\hline & 43 & 7 & $0-18$ & 1: 1 & 2007 & None & $1 \times$ strange taste \\
\hline & 5 & $?$ & $0-16$ & 1: 1 & $2004(-7)^{\mathrm{a}}$ & None & None \\
\hline & 20 & 10 & $2-19$ & $1: 2$ & 2006 & Levovist & None \\
\hline & 43 & $?$ & $0-18$ & $?$ & 2007 & Levovist & $\begin{array}{l}2 \times \text { strange taste, } \\
\text { cutaneous reaction }\end{array}$ \\
\hline & 19 & 10.3 & $0-23$ & 1.4: 1 & 2007 & Levovist & None \\
\hline & 26 & 9.8 & $0-15$ & 4: 22 & 2007 & n.c. & None \\
\hline & 30 & 5 & $0-15$ & $?$ & 2008 & None & None \\
\hline & 10 & 7 & $?$ & $?$ & 2009 & n.c. & None \\
\hline & 20 & 9 & $0-15$ & 1: 1 & 2008 & Levovist & None \\
\hline & 30 & 12 & $0.2-18$ & $19: 11$ & 2006 & None & $1 \times$ cutaneous reaction \\
\hline & 6 & 2 & $0-4$ & $?$ & only in 2009 & n.c. & None \\
\hline & 2 & 16.5 & 16,17 & 1: 1 & $2007(-10)^{\mathrm{a}}$ & None & None \\
\hline & 6 & 12 & $7-18$ & $2: 8$ & 2009 & n.c. & None \\
\hline & 3 & 16 & $15-17$ & 2: 1 & 2009 & Levovist & None \\
\hline & 15 & 9 & $0-18$ & 1: 1 & 2003 & None & None \\
\hline & 14 & 15 & $10-17$ & $?$ & 2005 & n.c. & None \\
\hline & 15 & 8 & $5-16$ & 1: 1 & 2009 & n.c. & None \\
\hline & 80 & 8 & $0-18$ & 1: 1 & 2008 & n.c. & $1 \times$ hyperventilation \\
\hline & 2 & 17 & 17 & 1: 1 & 2008 & n.c. & None \\
\hline & 10 & 10 & $1-16$ & 1: 1 & 2001 & n.c. & None \\
\hline & 2 & $?$ & $?$ & $?$ & 2002 & n.c. & None \\
\hline & 4 & 14 & $10-18$ & 1: 1 & 2007 & n.c. & None \\
\hline & 10 & 12 & -17 & $1: 3$ & 2008 & Levovist & None \\
\hline & 22 & $?$ & $3-17$ & 1: 1 & 2003 & n.c. & None \\
\hline & 10 & $?$ & $>6$ & $?$ & 2008 & Levovist & None \\
\hline & 1 & 17 & -17 & $0: 1$ & 2009 & n.c. & None \\
\hline & 7 & 10 & $10-17$ & $3: 4$ & 2010 & n.c. & None \\
\hline & 5 & 7.8 & $1-17$ & $?$ & 2007 & n.c. & None \\
\hline & 475 & $?$ & $1-17$ & $?$ & 2002 & n.c. & None \\
\hline \multicolumn{8}{|c|}{30 centres } \\
\hline Total & 948 & 5 & $0-19$ & ca $1: 2$ & & & $\begin{array}{l}5 \text { patients; } 6 \text { symptoms; } \\
1 \text { patient had } 2 \text { symptoms } \\
\text { and strange taste) }\end{array}$ \\
\hline
\end{tabular}

${ }^{a}$ Data are provided only for the given time span (e.g. because not used before or since)

n.c. No comment given

such as assessment of the urethra, have been overcome, and the potential to combine ce-VUS with sonographic genitography has also been demonstrated [70-75]. A recent metaanalysis of the existing literature on comparative studies of ce-VUS with voiding cystourethrography (VCUG) and direct radionuclide cystography (DRNC) confirmed the high sensitivity and specificity of this elegant nonionising imaging modality [76]. The data included more than 2,549 children with more than 5,078 pelvi-ureteric units. Using VCUG as the reference method, ce-VUS had a sensitivity of $90 \%$ and specificity of $92 \%$, with a high correlation of VUR grading. Compared to DRNC, ce-VUS yielded a sensitivity of $94 \%$ and a specificity of $95 \%$. More, and up to $10 \%$ higher graded, VURs were detected on ce-VUS; intrarenal reflux can also be depicted by ce-VUS. Additionally, perineal ce-VUS of the urethra enables excellent imaging of urethral anatomy, as demonstrated in 880 patients. In more than $97 \%$ of these patients, urethral assessment was reported feasible and reliable. The diagnostic performance of ce-VUS with SonoVue ${ }^{\circledR}$, the most widely used US-CA agent in 
Europe, did not differ significantly from Levovist ${ }^{\circledR}$; actually, SonoVue ${ }^{\circledR}$ performed slightly better. In some institutions, particularly when Levovist ${ }^{\circledR}$ was still available and registered for paediatric use, VCUG and DRNC are being gradually, or have been, replaced by ce-VUS, reducing the number of ionising studies significantly [77]. Less data are available on IV CE-US in children. The results of the few reports are similar to those from adults, and prove the high diagnostic potential of US-CAs in reducing the need for radiation-burdened imaging, particularly also in investigations of moderate blunt abdominal trauma [78-82].

In the United States, differences in practice and regulatory requirements have hampered the use of US-CAs. Nonetheless, two US-CAs (Definity ${ }^{\circledR}$, [Lanthaeus Medical Imaging, N. Billerica, MA] and Optison ${ }^{\circledR}$ [General Electric, Princeton, NJ]) are approved, but only for echocardiography. Regarding noncardiac use, a phase III study is underway by Bracco (Milan, Italy) to evaluate the use of SonoVue ${ }^{\circledR}$ for focal liver lesion characterisation. There are also a few institutions conducting animal or clinical studies pertaining to paediatric applications. Additionally, the Society of Pediatric Radiology (SPR) recently established a Contrast-enhanced Ultrasound (CE-US) Task Force with the objective of raising awareness among paediatric radiologists of the use of CE-US in children and to advise the FDA with regards to approval of US-CAs for paediatric use.

On balance, it seems logical to recommend CE-US for specific indications, particularly as CE-US would reduce significantly the exposure of children to radiation and iodinated $\mathrm{CA}$, and specifically taking into account the extremely low rate of drug-related adverse events reported to date $[32,53,54$, $83,84]$. This is even more important when compared with the potential long-term harmful effects of CT, particularly in children who have higher radiation sensitivity and a longer expected life span. This increasing awareness of the negative effects of radiation may spur the search for alternatives and suggests the use of US-CAs also in paediatric imaging.

The data from this Europe-wide questionnaire-based survey suggests a high safety profile of the US-CA SonoVue ${ }^{\circledR}$ and additionally demonstrates that there is not only a medical need, but also a potential market for paediatric US-CAs applications.

However, some restrictions of this survey have to be addressed. The response rate to the survey could not be properly assessed, as the number of recipients could not be tracked properly for many reasons: There was often more than one recipient per institution, no feedback of receipt of message, or different distribution pathways with partially significant overlaps between the various e-mail groups. However, as only one completed survey was submitted per institution, no data overlap in the CE-US application data appears to be present. It has to be additionally acknowledged that conventionally US is a primarily noninvasive study (that can be performed by radiographers, as it is standard for US in some parts of the world); performing a ce-US would make the investigation a more invasive study - by having to administer the US-CA either intravenously or into the respective cavity, mostly via catheter, which would require a physician to be present. However, if it helps reduce more threatening risks such as radiation hazards and does not exceed the invasiveness of the respective alternative technique (e.g. CT or MRI need IV-CA, too, VCUG requires catheterism and CA), CEUS appears justified. Still, proper precautions must be taken (i.e. one needs to have potentially necessary medication at hand, and staff who are qualified to administer the US-CA and to perform the examination, etc. ), and adequate reimbursement has to be eventually granted.

Additionally, caution should be used with IV applications in patients who are prone to increased allergic risk (e.g. suffering from multiple other allergies, particularly after repeated US-CA applications), in particularly endangered organs (such as the brain and eye) or where gas interfaces may cause cavitation-induced damage (i.e. lung and intestines), as well as in neonates, because the potential side effects have not been studied in detail and, additionally, cellular effects from the US-CA have been observed in vitro. Furthermore, data from small animal models suggest that glomerular capillary haemorrhage and other microvascular rupture may occur upon exposure to high sound pressure [85]. But most of the presently applied contrast imaging techniques are "low MI" techniques that use low energy and low sound pressure, thus making these aspects unlikely to affect CE-US in clinical practice [86]. Nevertheless, further studies on the safety of intracavitary and, particularly, intravesical SonoVue ${ }^{\circledR}$ applications will be necessary, as these have been performed only for Levovist ${ }^{\circledR}$ - a different agent consisting of air microbubbles and a sugar macromolecule.

Finally, it must be acknowledged that only the data submitted could be analysed and used. Some data gaps are obvious on the sheets (e.g. incomplete age information, the date since when the US-CA was used how many and which abdominal organs were imaged for what indication, etc.), and no validation of the correctness of the submitted data could be performed. Also, other systemic bias deriving from such retrospective surveys has to be considered, e.g. the lack of a common standard of recording of adverse effects, and one might speculate that those who advocate and support CE-US in children might have been more eager to answer than others. However, this does not affect the total numbers of documented paediatric CE-US applications, and our results match those of existing literature reports [26-29, 76, 84].

Nevertheless, knowledge of existing experience might be valuable for discussion and to promote the use of US-CAs and research in this field. The data from this survey-together with the information available in literature - may support the undertaking to eventually achieve paediatric licensing for US-CAs, as these observations suggest and demonstrate a 
good safety profile, clinically important and valuable applications, and a potentially reasonable market. There is also a first of its kind joint effort in pushing for licensing of US-CAs for paediatric use by a number of major societies (ESPR, ESUR, GPR, ESR Ultrasound Section, EFSUMB, WFUMB, SPR) $[87,88]$. The manufacturer Bracco (Bracco, Milan, Italy) has agreed to start an internal assessment on the possible inclusion of new indications, i.e. the paediatric use of SonoVue ${ }^{\circledR}$. This statement at the uroradiology task force session during the International Paediatric Radiology Meeting in London in June 2011 raises optimism $[88,89]$. The data from this survey may help to bring together the aspects of clinical importance, safety and use of US-CAs in infants and children.

\section{Conclusion}

This questionnaire-based European survey demonstrates that there are important applications for CE-US throughout childhood. Particularly, VUR assessment by ce-VUS could contribute to significantly reduce the exposure of this group of patients to diagnostic radiation. Furthermore, the survey suggests a high safety profile of US-CA SonoVue ${ }^{\circledR}$ and a potential reasonable market, thus making approval also economically more interesting, particularly taking into account all the comments stating willingness and eagerness to use US-CAs once they are made available and are approved for paediatric application. Hopefully, all this will spur interest in discussing and re-evaluating the use and approval of CE-US in children. For the time being, these experiences and the information from this survey can serve as valuable objective information when discussing an informed consent for off-license use of US-CAs, particularly SonoVue ${ }^{\circledR}$, with patients, parents and/or guardians.

Disclosure I certify that there is no actual or potential conflict of interest in relation to this article, and no financial or other interest concerning the reported topic

\section{References}

1. Ascenti G, Zimbaro G, Mazziotti S et al (2004) Harmonic US imaging of vesicoureteric reflux in children: usefulness of a second generation US contrast agent. Pediatr Radiol 34:481-487

2. Berrocal T, Gaya F, Arjonilla A et al (2001) Vesicoureteral reflux: diagnosis and grading with echo-enhanced cystosonography versus voiding cystourethrography. Radiology 221:359-365

3. Bosio M (1998) Cystosonography with echocontrast: a new imaging modality to detect vesicoureteric reflux in children. Pediatr Radiol 28:250-255

4. Darge K, Dütting T, Zieger B et al (1998) Diagnosis of vesicoureteral reflux with echo-enhanced voiding urosonography. Radiologe 38:405-409

5. Darge K, Troeger J, Duetting T et al (1999) Reflux in young patients: comparison of voiding US of the bladder and retrovesical space with echo enhancement versus voiding cysto-urethrography for diagnosis. Radiology 210:201-207
6. Darge K, Troeger J (2002) Vesicoureteral reflux grading in contrastenhanced voiding urosonography. Eur J Radiol 43:122-128

7. Darge K, Beer M, Gordjani N et al (2004) Contrast-enhanced voiding urosonography with the use of a 2nd generation US contrast medium: preliminary results. Pediatr Radiol 34:S97

8. Darge K, Moeller RT, Trusen A et al (2004) Diagnosis of vesicoureteric reflux with low-dose contrast-enhanced harmonic ultrasound imaging. Pediatr Radiol 35:73-78

9. Darge K (2008) Voiding urosonography with ultrasound contrast agents for the diagnosis of vesicoureteric reflux in children. I. Procedure. Pediatr Radiol 38:40-53

10. Darge K (2008) Voiding urosonography with US contrast agents for the diagnosis of vesicoureteric reflux in children. II. Comparison with radiological examinations. Pediatr Radiol 38:54-63, quiz 126-127

11. Darge K (2010) Voiding urosonography with US contrast agent for the diagnosis of vesicoureteric reflux in children: an update. Pediatr Radiol 40:956-962

12. Kenda RB, Novljan G, Kenig A et al (2000) Echo-enhanced ultrasound voiding cystography in children: a new approach. Pediatr Nephrol 14:297-300

13. Kmetec A, Bren AF, Kandus A et al (2001) Contrast-enhanced ultrasound voiding cystography as a screening examination for vesicoureteral reflux in the follow-up of renal transplant recipients: a new approach. Nephrol Dial Transplant 16:120-123

14. Kopitzko A, Cornely D, Reither K et al (2004) Low contrast dose voiding urosonography in children with phase inversion imaging. Eur Radiol 14:2290-2296

15. McEwing RL, Hellewell S, Anderson NG et al (2002) Comparison of echo-enhanced ultrasound with fluoroscopic MCU for the detection of vesicoureteral reflux in neonates. Pediatr Radiol 32:853-858

16. Mentzel HJ, Vogt S, Joan U et al (2002) Voiding urosonography with ultrasonography contrast medium in children. Pediatr Nephrol 17:272-276

17. Papadopoulou F, Anthopoulou A, Siomou E et al (2009) Harmonic voiding urosonography with a second-generation contrast agent for the diagnosis of vesicoureteral reflux. Pediatr Radiol 39:239-244

18. Piaggio G, Degl'Innocenti ML, Toma P et al (2003) Cystosonography and voiding cysto-urethrography in the diagnosis of vesicoureteral reflux. Pediatr Nephrol 18:18-22

19. Radmayr C, Klauser A, Pallwein L et al (2002) Contrast enhanced reflux sonography in children: a comparison to standard radiological imaging. J Urol 167:1428-1430

20. Riccabona M (2002) Cystography in infants and children: a critical appraisal of the many forms with special regard to voiding cystourethrography. Eur Radiol 12:2910-2918

21. Riccabona M, Mache CJ, Lindbichler F (2003) Echo-enhanced color Doppler cystosonography of vesicoureteral reflux in children: Improvement by stimulated acoustic emission. Acta Radiol 44:18-23

22. Valentini AL, Salvaggio E, Manzoni C et al (2001) Contrast enhanced gray-scale and color Doppler voiding urosonography versus voiding cystourethrography in the diagnosis and grading of vesicoureteral reflux. J Clin Ultrasound 29:65-71

23. Valentini AL, De Gaetano AM, Destito C et al (2002) The accuracy of voiding urosonography in detecting vesico-ureteral reflux: a summary of existing data. Eur J Pediatr 161:380-384

24. Zimbaro G, Ascenti G, Visalli C et al (2007) Contrast-enhanced ultrasonography (voiding urosonography) of vesicoureteral reflux: state of the art. Radiol Med 112:1211-1224

25. Riccabona M, Avni FE, Blickman JG et al (2008) Imaging recommendations in paediatric uroradiology: minutes of the ESPR workgroup session on urinary tract infection, fetal hydronephrosis, urinary tract ultrasonography and voiding cystourethrography. Barcelona, Spain, June 2007. Pediatr Radiol 38:138-145

26. Albrecht T, Blomley M, Bolondi L et al (2004) Guidelines for the use of contrast agents in ultrasound. Ultraschall Med 25:249-256 
27. Claudon M, Cosgrove D, Albrecht T et al (2008) Guidelines and good clinical practice recommendations for contrast enhanced ultrasound (CEUS) - update 2008. Ultraschall Med 29:28-44

28. Piscaglia F, Nolsoe C, Dietrich CF et al (2011) The EFSUMB guidelines and recommendations on the Clinical Practice of Contrast Enhanced Ultrasound (CEUS): update 2011 on non-hepatic applications. Ultraschall Med 32:1-27

29. Piskunowicz M, Kosiak W, Bratko T (2012) Intravenous application of second-generation ultrasound contrast agents in children: a review of the literature. Ultraschall Med 33:135-140

30. Correas JM, Bridal L, Lesavre A et al (2001) Ultrasound contrast agents: properties, principles of action, tolerance, and artifacts. Eur Radiol 11:1316-1328

31. Harvey CJ, Blomley MJK, Eckersley RJ et al (2001) Developments in ultrasound contrast media. Eur Radiol 11:675-689

32. Quaia E (ed) (2005) Contrast media in ultrasonography: basic principles and clinical applications. Springer, Berlin

33. Quaia E (2007) Microbubble ultrasound contrast agents: an update. Eur Radiol 17:1995-2008

34. Burns PN, Wilson SR, Hope Simpson D (2000) Pulse Inversion Imaging of liver blood flow: an improved method for characterization of focal masses with microbubble contrast. Invest Radiol 35:58-71

35. Hope Simpson D, Chin CT, Burns PN (1999) Pulse inversion Doppler: a new method for detecting nonlinear echoes from microbubble contrast agents. IEEE Trans Ultrason Ferroelec Freq Contr 46:372-382

36. Lencioni R, Cioni D, Bartolozzi C (2002) Tissue harmonic and contrast specific imaging: back to gray scale in ultrasound. Eur Radiol 12:151-165

37. Tetsuya K (2002) Technical description of 1.5-harmonic imaging, an effective technique for contrast-enhanced ultrasound diagnosis. Med Rev 87:22-25

38. Borsboom JM, Chin CT, de Jong N (2003) Nonlinear coded excitation method for ultrasound contrast imaging. Ultrasound Med Biol 29:277-284

39. Blomley MJK, Albrecht T, Cosgrove DO et al (1998) Stimulated acoustic emission in liver parenchyma with Levovist. Lancet 351:568-569

40. Whittingham T (2005) Contrast-specific imaging techniques: technical perspective. In: Quaia E (ed) Contrast media in ultrasonography: basic principles and clinical applications. Springer, Berlin, pp 43-70

41. Berry JD, Sidhu PS (2004) Microbubble contrast-enhanced ultrasound in liver transplantation. Eur Radiol 14(Suppl 8):P96-P103

42. Bryant T, Blomley MJK, Albrecht T et al (2004) Improved characterization of liver lesions with liver-phase uptake of liver specific microbubbles: prospective multicenter trials. Radiology 232:799-809

43. Dietrich CF, Kratzer W, Strobe D et al (2006) Assessment of metastatic liver disease in patients with primary extrahepatic tumors by contrast-enhanced sonography versus CT and MRI. World J Gastroenterol 12:1699-1705

44. Gasparini C, Bertolotto M, Croce SL et al (2003) Evaluation of liver parenchymal blood flow with contrast-enhanced US: preliminary results in healthy and cirrhotic patients. Acad Radiol 10:869-876

45. Leen E, Ceccotti P, Kalogeropoulou C et al (2006) Prospective multicenter trial evaluating a novel method of characterizing focal liver lesions using contrast- enhanced sonography. AJR 186:1551-1559

46. Nicolau C, Catalá V, Vilana R et al (2004) Evaluation of hepatocellular carcinoma using SonoVue, a second generation ultrasound contrast agent: correlation with cellular differentiation. Eur Radiol 14:1092-1099

47. Oldenburg A, Hohmann J, Foert E et al (2005) Detection of hepatic metastases with low MI real time contrast enhanced sonography and SonoVue. Ultraschall Med 26:277-284

48. Quaia E, D'Onofrio M, Palumbo A et al (2006) Comparison of contrast-enhanced ultrasonography vs baseline ultrasound and contrast-enhanced computed tomography in metastatic disease of the liver: diagnostic performance and confidence. Eur Radiol 16:1599-1609
49. Quaia E, Bertolotto M, Calderan L et al (2003) US characterization of focal hepatic lesions with intermittent high acoustic power mode and contrast material. Acad Radiol 10:739-750

50. Quaia E, Bartolotta TV, Midiri M et al (2006) Analysis of different contrast enhancement patterns after microbubble-based contrast agent injection in liver hemangiomas with atypical appearance at baseline scan. Abdom Imag 31(1):59-64

51. Rossi S, Rosa L, Ravetta V et al (2006) Contrast-enhanced versus conventional and color Doppler sonography for the detection of thrombosis of the portal and hepatic venous system. AJR 186:763-773

52. Wilson SR, Burns P (2006) An algorithm for the diagnosis of focal liver masses using microbubble contrast-enhanced pulse-inversion sonography. AJR 186:1401-1412

53. Piscaglia F, Bolondi L (2006) The safety of Sonovue in abdominal applications: retrospective analysis of 23188 investigations. Ultrasound Med Biol 32:1369-1375

54. Morel DR, Schwieger I, Hohn L et al (2000) Human pharmacokinetics and safety evaluation of SonoVue, a new contrast agent for ultrasound imaging. Invest Radiol 35:80-85

55. Catalano O, Sandomenico F, Matarazzo I et al (2005) Contrastenhanced sonography of the spleen. AJR 184:1150-1156

56. Cassano E, Rizzo S, Bozzini A et al (2006) Contrast enhanced ultrasound of breast cancer. Cancer Imaging 31:4-6

57. Correas JM, Claudon M, Tranquart F et al (2006) The kidney: imaging with microbubble contrast agents. Ultrasound Q 22:53-66

58. Halpern EJ, Frausher F, Rosemberg M et al (2002) Directed biopsy during contrast-enhanced sonography of the prostate. AJR 178:915-919

59. Holsher T, Wilkening W, Draganski B et al (2005) Transcranial ultrasound brain perfusion assessment with a contrast agentspecific imaging mode: results of a two-center trial. Stroke 36:2283-2285

60. Klauser A, Demharter J, De Marchi A et al (2005) Contrast enhanced grayscale sonography in assessment of joint vascularity in rheumatoid arthritis: results from the IACUS study group. Eur Radiol 15:2404-2410

61. Krix M, Kiessling F, Farhan N (2003) A multivessel model describing replenishment kinetics of ultrasound contrast agent for quantification of tissue perfusion. US Med Biol 29:1421-1430

62. McCarville MB, Streck CJ, Dickson PV et al (2006) Angiogenesis inhibitors in a murine neuroblastoma model: quantitative assessment of intratumoral blood flow with contrast-enhanced gray-scale US. Radiology 240:73-81

63. Paltiel HJ, Kalish LA, Susaeta RA et al (2006) Pulse inversion US imaging of testicular ischemia: quantitative and qualitative analyses in a rabbit model. Radiology 239:718-729

64. Quaia E, Siracusano S, Bertolotto M et al (2003) Characterization of renal tumours with pulse inversion harmonic imaging by intermittent high mechanical index technique: preliminary results. Eur Radiol 13:1402-1412

65. Rubaltelli L, Khadivi Y, Tregnaghi A et al (2004) Evaluation of lymph node perfusion using continuous mode harmonic ultrasonography with a second generation contrast agent. J Ultrasound Med 23:829-836

66. Stieger SM, Bloch SH, Foreman O et al (2006) Ultrasound assessment of angiogenesis in a matrigel model in rats. Ultrasound Med Biol 32:673-681

67. Siösteen AK, Elvin A (2004) Intraoperative uses of contrastenhanced ultrasound. Eur Radiol 14(Suppl 8):P87-P95

68. Weber MA, Krix M, Jappe U et al (2005) Pathologic skeletal muscle perfusion in patients with myositis: detection with quantitative contrast enhanced US-initial results. Radiology 238:640-649

69. Wei K, Ragosta M, Thorpe J et al (2001) Non-invasive quantification of coronary blood flow reserve in humans using myocardial contrast echocardiography. Circulation 103:2560-2565 
70. Berrocal T, Rivas S, Jaureguizar E et al (2004) Contrast-enhanced sonourethrography in the assessment of the urethra. Cir Pediatr 17:58-60

71. Berrocal T, Gaya F, Arjonilla A (2005) Vesicoureteral reflux: can the urethra be adequately assessed by using contrast-enhanced voiding US of the bladder? Radiology 234:235-241

72. Bosio M, Manzoni GA (2002) Detection of posterior urethral valves with voiding cysto-urethrosonography with echo contrast. J Urol 168:1711-1715

73. Duran C, Valera A, Alguersuari A et al (2009) Voiding urosonography: the study of the urethra is no longer a limitation of the technique. Pediatr Radiol 39:124-131

74. Maté A, Bargiela A, Mosteiro S et al (2003) Contrast ultrasound of the urethra in children. Eur Radiol 13:1534-1537

75. Kopac M, Riccabona M, Haim M (2009) Contrast-enhanced voiding urosonography and genitography in a baby with ambiguous genitalia and urogenital sinus. Ultraschall Med 30:299-300

76. Papadopoulou F, Evangelou E, Darge K (2011) Contrast-enhanced voiding urosonography for diagnosis of vesicoureteric reflux in comparison to conventional methods: a meta-analysis. Oral presentation at the ESPR Pediatric Uroradiology Task Force session during the IPR in London, 28 May 2011

77. Darge K, Zieger B, Rohrschneider W et al (2001) Reduction in voiding cystourethrographies after the introduction of contrast enhanced sonographic reflux diagnosis. Pediatr Radiol 31:790-795

78. Catalano O, Cusati B, Nunziata A et al (2006) Active abdominal bleeding: contrast-enhanced sonography. Abdom Imaging 31:9-16

79. Oldenburg A, Hohmann J, Skrok J et al (2004) Imaging of paediatric splenic injury with contrast-enhanced ultrasonography. Pediatr Radiol 34:351-354

80. Sparano A, Acampora C, di Nuzzo L et al (2006) Color power Doppler US and contrast-enhanced US features of abdominal solid organ injuries. Emerg Radiol 12:216-222
81. Thorelius L (2004) Contrast-enhanced ultrasound in trauma. Eur Radiol 14(Suppl 8):P43-P52

82. Valentino M, Serra C, Pavlica P et al (2008) Blunt abdominal trauma: diagnostic performance of contrast-enhanced US in children-initial experience. Radiology 246:903-909

83. Nolsoe C, Piscaglia F, Dietrich CF et al (2011) Primum non nocere? Why can't we use second generation Ultrasound Contrast Agents for the examination of children? Ultraschall Med 32:83-86

84. Torzilli G (2005) Adverse effects associated with SonoVue use. Expert Opin Drug Saf 4:399-401

85. ter Haar G (2009) Safety and bio-effects of ultrasound contrast agents. Med Biol Eng Comput 47:893-900

86. Quaia E (2007) Contrast-specific ultrasound techniques. Radiol Med 112:473-490

87. Riccabona M, Claudon M, Derchi L et al (2011) Statement of the ESPR Uroradiology Task Force and the ESUR Paediatric Work Group concerning the use and availability of ultrasound contrast agents in children. Open letter to the European Medicines Agency from November 2011. Pediatr Radiol

88. Riccabona M (2011) Report on the meeting of representatives of ESPR, ESUR, WFUMB/EFSUMB, GRP, ECR, AIUM and SPR with Bracco during the IPR in London, May 9th 2011, on paediatric approval for SonoVue ${ }^{\circledR}$. On behalf of the ESPR Paediatric Uroradiology Task Force. ESPR website: www.espr.org/index.php? option $=$ com_content\&view $=$ article \&id $=213$ :uro-radiology-tfreport-of-the-sonovue-meeting-ipr-2011\&catid=1

89. Riccabona M, Avni F, Damasio B et al (2011) Report on the public session of the ESPR Paediatric Uroradiology Task Force during the IPR in London, May 28th 2011- a joint activity with the ESUR Paediatric Working Group. ESPR newsletter 2011 at ESPR website: www.espr.org/index.php?option $=$ com_content\&view $=$ article \&id=212:report-of-the-meeting-ipr-2011\&catid=133:uroradiology-task-force-reports-a-protocols \&Itemid $=135$ 